\title{
Aplikasi Persamaan Bessel Orde Nol Pada Persamaan Panas Dua dimensi
}

\author{
Annisa Eki Mulyati dan Sugiyanto \\ Program Studi Matematika Fakultas Sains dan Teknologi, UIN Sunan Kalijaga, Jl. Marsda Adisucipto \\ No. 1 Yogyakarta, Indonesia
}

Korespondensi; Annisa Eki Mulyati,Email: eky_nyzha@yahoo.com

\begin{abstract}
Abstrak
Persamaan diferensial Bessel adalah salah satu persamaan yang diterapkan dalam fisika adalah tentang perpindahan panas. Penerapan fungsi Bessel yang dimodifikasi dari perintah nol pada proses perpindahan panas dari objek dua dimensi yang dapat dimodelkan dalam bentuk persamaan diferensial parsial dua orde sebagai berikut, $\alpha \cdot \frac{\partial u}{\partial t}(r, \theta, t)=\frac{1}{r} \frac{\partial u}{\partial r}+\frac{\partial^{2} u}{\partial r^{2}}+\frac{1}{r^{2}} \frac{\partial^{2} u}{\partial \theta^{2}}$. Dengan mendapatkan solusi persamaan diferensial Bessel dari sirip lingkaran, $u(r, \theta, t)=\left(C_{n} \sin \sqrt{\delta_{2 n}}\right) J_{0}\left(r \sqrt{\delta_{1}-\delta_{2}}\right) e^{-\delta_{1} \alpha t}$ dua dimensi Suhu dinyatakan pada titik $(r, \theta)$ terhadap waktu $t$.
\end{abstract}

Kata Kunci: Persamaan diferensial Bessel; Fungsi Bessel dari urutan nol; Perpindahan panas

\begin{abstract}
Bessel differential equation is one of the applied equation in physics is about heat transfer. Application of modified Bessel function of order zero on heat transfer process of two-dimensional objects which can be modelled in the form of a two-order partial differential equations as follows, $\alpha \cdot \frac{\partial u}{\partial t}(r, \theta, t)=\frac{1}{r} \frac{\partial u}{\partial r}+\frac{\partial^{2} u}{\partial r^{2}}+\frac{1}{r^{2}} \frac{\partial^{2} u}{\partial \theta^{2}}$. With the obtained solutions of Bessel's differential equation application of circular fin, $u(r, \theta, t)=\left(C_{n} \sin \sqrt{\delta_{2 n}}\right) J_{0}\left(r \sqrt{\delta_{1}-\delta_{2}}\right) e^{-\delta_{1} \alpha t}$ two-dimensional temperature stated on the point $(r, \theta)$ against time $t$.
\end{abstract}

Keywords: Bessel differential equation; Bessel function of order zero; Heat transfer

\section{Pendahuluan}

Matematika adalah salah satu disiplin ilmu eksakta yang mencoba merepresentasikan mengenai fenomena alam. Oleh karena itu, Matematika juga dapat dikatakan sebagai dasar dari beberapa disiplin ilmu lainnya seperti Fisika, Biologi, Kimia, Teknik bahkan Ekonomi. Pada Matematika, terdapat pembahasan lebih dalam lagi tentang pengkajian teori teorinya. Berdasarkan objeknya pengkajiannya Matematika dikelompokan menjadi beberapa pembahasan antara lain Matematika terapan, Statistika, Aljabar, Analisis, dan Komputasi.

Pada perkembangannya ilmu Matematika banyak digunakan dalam bidang ilmu lain, begitu juga dengan banyaknya teori-teori matematika yang menjadi dasar dalam pembahasan ataupun pengkajiannya. Pada penelitian ini kaitaan ilmu Matematika dengan pengkajian bidang ilmu lain, akan lebih banyak dibahas pada ilmu Fisika dan Teknik. Salah satu teori Matematika yang dikaji lebih rinci dibidang ilmu Fisika ataupun Teknik adalah teori Persamaan Diferensial atau disebut PD.

Pembahasan mengenai PD dimulai setelah penemuan Kalkulus dan Integral. Pada tahun 1676 Isaac Newton telah berhasil menyelesaikan sebuah PD menggunakan deret tak hingga, tetapi Newton tidak mempublikasikan hal tersebut sampai dengan tahun 1693, pada saat itu Gotfried Wilhelm Leibniz menghasilkan rumusan PD yang pertama. PD mulai berkembang dari tahun ketahun. Pada tahun 16941697 John Bernoulli menjelaskan Metode Pemisahan Variabel dan membuktikan bahwa PD homogen orde satu dapat direduksi menjadi bentuk PD dengan variabel variabel yang dapat dipisahkan. 
Pada tahun 1784-1846 pengkajian PD mulai disempurnakan disempurnakan salah satunya oleh Friedrich Wilhelm Bessel, seorang matematikawan Jerman yang juga astronom. Bessel mempublikasikan penelitiannya melalui makalah yang diterbitkan tahun 1826 yang disebut Persamaan Diferensial Bessel. Bentuk umum PD Bessel adalah $x^{2} y^{\prime \prime}+x y^{\prime}+\left(x^{2}-n^{2}\right) y=0$. Solusi dari PD Bessel disebut dengan fungsi Bessel. Pada penyelesaian fungsi Bessel terdapat tiga order, yaitu order bukan bilangan bulat, order bilangan bulat dan order nol. Bentuk penyelesaian umum PD Bessel adalah: $y(x)=C_{1} J_{n}(x)+$ $C_{2} Y_{n}(x)$, dengan $n$ menyatakan order Bessel.

PD Bessel merupakan salah satu PD yang diterapkan dalam ilmu Fisika yaitu mengenai perpindahan panas. Perpindahan Panas adalah berpindahnya energi panas atau kalor pada suatu benda dari bersuhu tinggi ke suhu rendah. PD Bessel pada masalah perpindahan panas di reduksi dari persamaan panas yang digunakan untuk mengetahui laju perpindahan panas. Persamaan panas yang akan dikaji lebih rinci yaitu persamaan panas dua dimensi. Benda dua dimensi adalah benda yang mempunyai ukuran luasan. Adapun contoh dari benda dua dimensi ini yaitu persegi panjang, kotak, segitiga, lingkaran dan lain sebagainya. Pada penelitian ini akan dikaji lebih khusus lagi pada benda dua dimensi yang berbentuk lingkaran. Lingkaran didefinisikan sebagai garis melengkung yang kedua ujungnya bertemu pada jarak yang sama dari titik pusat. Hal diatas yang melatarbelakangi penelitian ini yaitu tentang pengkajian secara matematis PD Bessel ketika ordernya sama dengan nol serta penerapannya dalam merepresentasikan laju perpindahan panas pada benda dua dimensi.

\section{Pembentukan Persamaan Panas Pada Koordinat Kartesius}

Perpindahan panas bergantung dari jenis bahan benda yang diamati, antara lain kalor jenis bahan $c$, konduktifitas themal bahan $k$, masa jenis bahan $\rho$. Persamaan konduksi panas dua dimensi dapat diturunkan melalui perubahan luas benda. Perubahan panjang pada sumbu kartesius dapat dilihat pada Gambar 1.

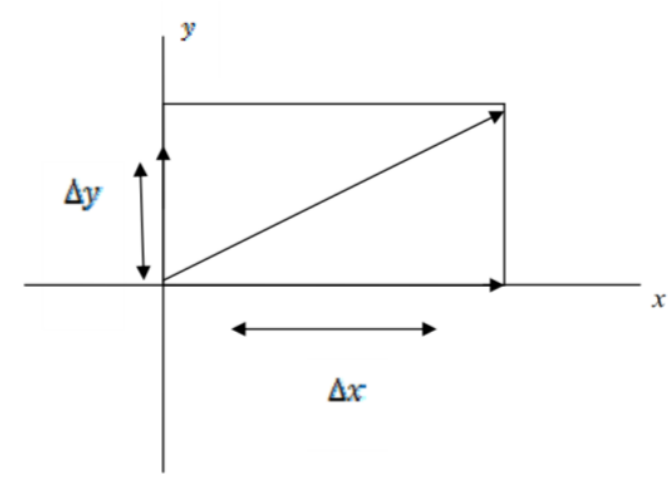

Gambar 1 Koordinat kartesius dua dimensi.

Perubahan luas pada benda dua dimensi disimbolkan dengan $\Delta L, \Delta L=\Delta x \Delta y$, dan $u(x, y, t)$ menyatakan suhu pada posisi $(x, y)$ pada saat waktu $t$. Oleh karena itu, perpindahan konduksi panas pada koordinat $x$ dan $y$ dapat diselesaikan dengan persamaan Fourier, yaitu $q=-k A u_{x}[1]$.

Persamaan Fourier digunakan untuk menentukan laju perpindahan panas dan laju perpindahan kondusksi panas pada benda, penjabarannya sebagai berikut. Pada koordinat $x$, laju perpindahan panas (dinotasikan dengan $q_{x}$ ), diperoleh dengan mengalihkan arus konduksi panas posisi $x$ dengan sisi bendanya yaitu $\Delta y$, sehingga diperoleh,

$$
q_{x}=-k A u_{x} \Delta y
$$

Sedangkan laju perpindahan konduksi panas di dalam benda, diperoleh dengan mengalihkan arus konduksi panas pada koordinat $x$ luas permukaan benda yang disimbolkan dengan $q_{x+\Delta x}$, maka diperoleh, 


$$
q_{x+\Delta x}=-\left[k A u_{x}+k A u_{x x}\right] \Delta y
$$

Laju perpindahan panas pada koordinat $y$ diperoleh dengan mengalihkan arus konduksi panas pada koordinat $y$ dengan luas permukaan benda, yang disimbolkan dengan $q_{y}$, maka akan diperoleh,

$$
q_{y}=q(y, t) \Delta x=-k A u_{y} \Delta x
$$

Sedangkan laju perpindahan konduksi panas di dalam benda, diperoleh dengan mengalihkan arus konduksi panas pada koordinat $x$ luas permukaan benda yang disimbolkan dengan $q_{x+\Delta x}$, maka diperoleh,

$$
q_{y+\Delta y}=-\left[k A u_{y}+k A u_{y y}\right] \Delta x
$$

Setelah diperoleh persamaan arus dan laju perpindahan panas pada koordinat benda, selanjutnya akan dijelaskan energi pada pada benda itu. Jika energi pada benda disimbolkan dengan $E$, maka jumlah energy benda adalah $E=c \rho \Delta x \Delta y \cdot u(x, y, t)$, dan jumlah energy pada benda berdasarkan koordinat $x$ dan $y$ pada wkatu $t$ adalah,

$$
E_{t}=c \rho A \Delta x \Delta y \cdot u_{t}(x, y, t)
$$

Berdasarkan [1] energi yang masuk ke dalam benda energi yang keluar dari benda sama dengan jumlah perubahan energi pada benda, secara matematika dapat masalah ini dituliskan sebagai berikut,

$$
E_{t}=\left(q_{x}+q_{y}\right)-\left(q_{x+\Delta x}+q_{x+\Delta x}\right)
$$

Selanjutnya, dengan mensubtitusikan persamaan (1), (2), (3), (4) dan (5) kedalam persamaan (6), maka akan diperoleh

$$
\begin{aligned}
c \rho A \Delta x \Delta y \cdot u_{t}(x, y, t) & =-\left(k A u_{x}+k A u_{y} \Delta x\right)-\left\{-\left[k A u_{x}+k A u_{x x}\right] \Delta y--\left[k A u_{y}+k A u_{y y}\right] \Delta x\right\} \\
& \Leftrightarrow c \rho A_{x y} \Delta x \Delta y \cdot u_{t}(x, y, t)=k A \Delta x \Delta y\left(u_{x x}+u_{y y}\right)
\end{aligned}
$$

Jika persamaan (7) di atas dibagi dengan $k A \Delta x \Delta y$ maka diperoleh,

$$
\frac{c \rho}{k} \cdot u_{t}(x, y, t)=\left(u_{x x}+u_{y y}\right)
$$

Selanjutnya, $\frac{c \rho}{k}=\alpha$ adalah konstanta penghambur panas. Jika nilai penghambur panas makin besar, maka makin cepat panas membaur pada benda. Oleh karena itu persamaan (8) akan menjadi,

$$
\alpha \cdot u_{t}(x, y, t)=u_{x x}+u_{y y}
$$

Persamaan (9) diatas disebut juga persamaan panas pada benda dua dimensi.

Terdapat beberapa contoh benda dua dimensi seperti benda yang memiliki luasan, antara lain segitiga, kotak, persegi panjang, lingkaran dan lain sebagainya. Pada penelitian ini benda dua dimensi yang akan di kaji yaitu sebuah benda yang berbentuk lingkaran. Hal ini dikarenakan untuk mempermudah pemahaman tentang benda dua dimensi dalam pengkajian di penerapan fungsi Bessel.

Selanjutnya, karena benda dua dimensi ini berbentuk lingkaran, maka terlebih dahulu akan diubah koordinatnya, dari koordinat kartesius ke koordinat lingkaran atau lebih dikenal dengan koordinat kutub. 


\section{Pembentukan Persamaan Panas Pada Koordinat Kutub}

Selanjutnya akan dijelaskan langkah-langkah dalam pembentukan persamaan panas pada koordinat kutub yaitu,

Langkah pertama, mengubah koordinat kartesius menjadi kutub.

Jika $u(x, y, t)$ pada koordinat kartesius, diubah ke koordinat kutup maka akan menjadi $u(r, \theta, t)$ ini menyatakan suhu pada posisi $(r, \theta)$ pada saat waktu $t$. Perubahan koordinat ini dengan memisalkan $x=r \cos \theta$ dan $y=r \sin \theta$, dan kemudian didapatkan turunan atau derivative pertama dan kedua.

Langkah kedua, mencari turunan parsial pertama dan kedua terhadap $r$ dan $\theta$ dari fungsi $u(x, y, t)$ yaitu,

Turunan parsial pertama terhadap $r$ yaitu,

$$
\frac{\partial u}{\partial r}=\frac{\partial u}{\partial x} \cos \theta+\frac{\partial u}{\partial y} \sin \theta
$$

Atau dapat dituliskan dalam bentuk,

$$
u_{r}=u_{x} \cos \theta+u_{y} \sin \theta
$$

Turunan parsial pertama terhadap $\theta$ yaitu,

$$
u_{\theta}=u_{x}(-r \sin \theta)+u_{y}(r \cos \theta)
$$

Berdasarkan persamaan (10) dan (11), dapat diperoleh turunan pertama terhadap $x$ dan $y$, dengan cara membentuk persamaan kedalam bentuk matriks, yaitu

$$
\left[\begin{array}{l}
u_{r} \\
u_{\theta}
\end{array}\right]=\left[\begin{array}{l}
u_{x} \\
u_{y}
\end{array}\right]\left[\begin{array}{cc}
\cos \theta & \sin \theta \\
-r \sin \theta & r \cos \theta
\end{array}\right]
$$

Selanjutnya, variabel $r$ dikeluarkan, dan ruas kanan dipindahkan kekiri, dan dengan menggunakan aturan matriks, maka akan diperoleh,

$$
\left[\begin{array}{l}
u_{x} \\
u_{y}
\end{array}\right]=\left[\begin{array}{ll}
u_{r} \cos \theta & u_{\theta} \frac{-\sin \theta}{r} \\
u_{r} \sin \theta & u_{\theta} \frac{\cos \theta}{r}
\end{array}\right]
$$

Turunan parsial kedua terhadap $r$ yaitu,

$$
\begin{aligned}
& u_{r r}=\frac{\partial}{\partial r}\left(u_{r}\right) \\
& \Leftrightarrow u_{r r}=u_{x x} \cos ^{2} \theta+2 u_{x y} \sin \theta \cos \theta+u_{y y} \sin ^{2} \theta \\
& \Leftrightarrow 2 u_{x y} \sin \theta \cos \theta=u_{x x} \cos ^{2} \theta+u_{y y} \sin ^{2} \theta-u_{r r}
\end{aligned}
$$

Turunan parsial kedua terhadap $\theta$ yaitu,

$$
\begin{aligned}
& u_{\theta \theta}=\frac{\partial}{\partial \theta}\left(u_{\theta}\right) \\
& \Leftrightarrow u_{\theta \theta}=r\left[-u_{x} \cos \theta-u_{y} \sin \theta\right]+r^{2}\left[u_{x x} \sin ^{2} \theta-2 u_{x y} \sin \theta \cos \theta+u_{y y} \cos ^{2} \theta\right]
\end{aligned}
$$


Jika fungsi $u_{x}, u_{y}$ yang telah diperoleh dari persamaan (12), dan fungsi $2 u_{x y} \sin \theta \cos \theta$ yang diperoleh pada persamaan (14), disubtitusi kedalam persamaan (15), maka diperoleh

$$
\begin{gathered}
\Leftrightarrow u_{\theta \theta}=r\left[-\left(u_{r} \cos \theta-\frac{u_{\theta} \sin \theta}{r}\right) \cos \theta-\left(u_{r} \cos \theta-\frac{u_{\theta} \sin \theta}{r}\right) \sin \theta\right] \\
+r^{2}\left[u_{x x} \sin ^{2} \theta+u_{x x} \cos ^{2} \theta+u_{y y} \sin ^{2} \theta-u_{r r}+u_{y y} \cos ^{2} \theta\right] \\
\Leftrightarrow u_{x x}+u_{y y}=\frac{1}{r} u_{r}+u_{r r}+\frac{1}{r^{2}} u_{\theta \theta}
\end{gathered}
$$

Langkah ketiga, untuk memperoleh persamaan panas, dengan cara mensubtitusi persamaan (15a) ke persamaan (9) maka diperoleh,

$$
\alpha \cdot u_{r}(r, \theta, t)=\frac{1}{r} u_{r}+u_{r r}+\frac{1}{r^{2}} u_{\theta \theta}
$$

Atau dapat dituliskan dalam bentuk

$$
\alpha \cdot \frac{\partial u}{\partial t}(r, \theta, t)=\frac{1}{r} \frac{\partial u}{\partial r}+\frac{\partial^{2} u}{\partial r^{2}}+\frac{1}{r^{2}} \frac{\partial^{2} u}{\partial \theta^{2}}
$$

Persamaan (16) disebut persamaan panas dua dimensi dalam bentuk koordinat kutub.

Selanjutnya, akan dijelaskan penerapan fungsi pada benda yang berbentuk lingkaran. Sebelumnya akan diberikan terlebih dahulu asumsi membatasi permasalahan yang disesuaikan dengan kondisi batasnya. Asumsi yang akan diberikan berupa syarat awal dan syarat batas.

\section{Syarat Awal dan Batas}

Jika suhu mula-mula pada waktu adalah $t_{0}=0$, maka $u\left(r, \theta, t_{0}\right)=u_{0}$ atau $u(r, \theta, 0)=0$. Suhu pada lingkaran yang dinyatakan dengan $u(r, \theta, t)$, menyatakan syarat awal suhu pada $(r, \theta), 0 \leq r \leq R$ dan $0 \leq \theta \leq 2 \pi$ pada saat waktu $t$. Suhu di sekitar lingkungan yaitu,

$$
\begin{array}{ll}
u(r, \theta, t)=u_{0}, & 0 \leq \theta \leq 2 \pi \\
u(r, 0, t)=u_{0} & 0 \leq r \leq R \\
u(r, 2 \pi, t)=u_{0} & 0 \leq r \leq R
\end{array}
$$

Dengan $u_{0}=0$

\section{Penyelesaian Model}

Pada penyelesaian model ini akan dijelaskan penyelesaian model persamaan panas pada lingkaran Metode yang digunakan adalah dengan separasi variabel. Penyelesaian dengan menggunakan separasi variabel, digunakan asumsi,

$$
u(x, t)=X(x) T(t)
$$


Jika diterapkan pada persamaan (16), akan dicari solusi pada setiap fungsinya, maka untuk langkah pertama mencari solusi untuk fungsi $T(t)$. Oleh karena itu asumsi separasi variabel menjadi,

$$
u(x, \theta, t)=X(r, \theta) T(t)
$$

Jika persamaan (18) disubtitusi ke persamaan (16), maka akan menjadi,

$$
\begin{aligned}
& \alpha \cdot \frac{\partial}{\partial t} A(r, \theta) T(t)= \frac{1}{r} \frac{\partial}{\partial r} A(r, \theta) T(t)+\frac{\partial^{2}}{\partial r^{2}} A(r, \theta) T(t) \\
&+\frac{1}{r^{2}} \frac{\partial^{2}}{\partial \theta^{2}} A(r, \theta) T(t) \\
& \Leftrightarrow \alpha \cdot A(r, \theta) \frac{\partial}{\partial t} T(t)= \frac{1}{r} T(t) \frac{\partial}{\partial r} A(r, \theta)+T(t) \frac{\partial^{2}}{\partial r^{2}} A(r, \theta)+ \\
& \frac{1}{r^{2}} T(t) \frac{\partial^{2}}{\partial \theta^{2}} A(r, \theta)
\end{aligned}
$$

Kemudian membagi persamaan (18) diatas dengan $X(r, \theta) T(t)$, maka akan menjadi,

$$
\begin{gathered}
\alpha \cdot \frac{1}{T(t)} \frac{\partial}{\partial t} T(t)=\frac{1}{r} \frac{1}{A(r, \theta)} \frac{\partial}{\partial r} A(r, \theta)+\frac{1}{A(r, \theta)} \frac{\partial^{2}}{\partial r^{2}} A(r, \theta)+ \\
\frac{1}{r^{2}} \frac{1}{A(r, \theta)} \frac{\partial^{2}}{\partial \theta^{2}} A(r, \theta) \\
\Leftrightarrow \alpha \cdot \frac{1}{T(t)} \frac{\partial}{\partial t} T(t)=\frac{1}{r} \frac{1}{A(r, \theta)} \frac{\partial}{\partial r} A(r, \theta)+\frac{1}{A(r, \theta)} \frac{\partial^{2}}{\partial r^{2}} A(r, \theta)+ \\
\frac{1}{r^{2}} \frac{1}{A(r, \theta)} \frac{\partial^{2}}{\partial \theta^{2}} A(r, \theta)=-\delta_{1}
\end{gathered}
$$

Dengan konstanta separasi variabel $=-\delta_{1}$, sehingga akan diperoleh, berdasarkan persamaan (20) maka diperoleh nilai dari fungsi $T(t)$ adalah,

$$
\alpha \frac{1}{T(t)} \frac{d}{d t} T(t)=-\delta_{1}
$$

Penyelesaian persamaan (21) menggunakan PD orde satu, maka penyelesaiannya adalah,

$$
\begin{aligned}
& \frac{d}{d t} T(t)=-\delta_{1} \alpha T(t) \\
& \Leftrightarrow T=e^{-\delta_{1} \alpha t}
\end{aligned}
$$

Jika $T(t) \neq 0$, maka $X(r, 0), X(r, 2 \pi)$ secara berurutan akan sama dengan nol.

Selanjutnya, langkah kedua mencari penyelesaian dari fungsi $\emptyset(\theta)$, maka asumsi dari persamaan (18), akan menjadi,

$$
X(r, \theta)=R(r) \emptyset(\theta)
$$


Persamaan (23) disubtitusikan ke persamaan (20) akan menjadi,

$$
\begin{gathered}
-\delta_{1}=\frac{1}{r} \frac{1}{R(r) \phi(\theta)} \frac{\partial}{\partial r} R(r) \phi(\theta)+\frac{1}{R(r) \phi(\theta)} \frac{\partial^{2}}{\partial r^{2}} R(r) \phi(\theta)+ \\
\frac{1}{r^{2}} \frac{1}{R(r) \phi(\theta)} \frac{\partial^{2}}{\partial \theta^{2}} R(r) \phi(\theta) \\
\Leftrightarrow-\delta_{1} R(r) \phi(\theta)=\frac{1}{r} \frac{\partial}{\partial r} \phi(\theta) R(r)+\phi(\theta) \frac{\partial^{2}}{\partial r^{2}} R(r) \\
+\frac{1}{r^{2}} R(r) \frac{\partial^{2}}{\partial \theta^{2}} \phi(\theta)
\end{gathered}
$$

Persamaan (24) dibagi dengan $R(r) \emptyset(\theta)$, maka akan menjadi,

$$
\begin{aligned}
& -\delta_{1}=\frac{1}{r} \frac{1}{R(r)} \frac{\partial}{\partial r} R(r)+\frac{1}{R(r)} \frac{\partial^{2}}{\partial r^{2}} R(r)+\frac{1}{r^{2}} \frac{1}{\phi(\theta)} \frac{\partial^{2}}{\partial \theta^{2}} \phi(\theta) \\
& \Leftrightarrow-\frac{1}{\phi(\theta)} \frac{\partial^{2}}{\partial \theta^{2}} \phi(\theta)=\frac{1}{r} \cdot r^{2} \frac{1}{R(r)} \frac{\partial}{\partial r} R(r)+r^{2} \frac{1}{R(r)} \frac{\partial^{2}}{\partial r^{2}} R(r)+\delta_{1} r^{2}
\end{aligned}
$$

Selanjutnya, persamaan diberikan konstanta separasi variabel $=-\delta_{2}$, sehingga akan diperoleh,

$$
\begin{aligned}
& -\left(-\delta_{2}\right)=r \frac{1}{R(r)} \frac{\partial}{\partial r} R(r)+r^{2} \frac{1}{R(r)} \frac{\partial^{2}}{\partial r^{2}} R(r)+r^{2} \delta_{1} \\
& \Leftrightarrow \quad \delta_{2}=r \frac{1}{R(r)} \frac{\partial}{\partial r} R(r)+r^{2} \frac{1}{R(r)} \frac{\partial^{2}}{\partial r^{2}} R(r)+r^{2} \delta_{1}
\end{aligned}
$$

Persamaan di atas dibagi dengan $R(r)$, maka persamaan menjadi

$$
\delta_{2} R(r)=r \frac{\partial}{\partial r} R(r)+r^{2} \frac{\partial^{2}}{\partial r^{2}} R(r)+\delta_{1} r^{2} R(r)
$$

Berdasarkan persamaan (24) akan diperoleh nilai dari fungsi $R(r)$ adalah,

$$
\begin{aligned}
& -\frac{1}{\phi(\theta)} \frac{\partial^{2}}{\partial \theta^{2}} \phi(\theta)=\delta_{2} \\
& \Leftrightarrow 0=\delta_{2} \phi(\theta)+\frac{\partial^{2}}{\partial \theta^{2}} \phi(\theta)
\end{aligned}
$$

Persamaan (26) akan diselesaikan dengan menggunakan PD orde dua. Pemisalkannya adalah

$$
\varnothing(\theta)=f \cdot e^{j \emptyset}
$$

Turunan pertama $\frac{d}{d \theta} \emptyset(\theta)=f . j e^{j \emptyset}=j \emptyset$ 
Turunan kedua $\frac{d^{2}}{d \theta^{2}} \emptyset(\theta)=f \cdot j^{2} e^{j \emptyset}=j^{2} \emptyset$

Pemisalan disubtitusikan ke persamaan (26), maka akan diperoleh bentuk,

$$
\begin{aligned}
& \delta_{2} j \emptyset+j^{2} \emptyset=0 \\
& \left(\delta_{2} j+j^{2}\right) \emptyset=0
\end{aligned}
$$

Diperoleh akar-akar karakteristik adalah $j_{1}=\sqrt{\delta_{2}} i$, dan $j_{2}=\sqrt{\delta_{2}} i$. Akar-akar karakteristik berupa dua akar kembar, berdasarkan penjabaran sebelumnya, maka penyelesaian dari persamaan (26) adalah,

$$
\emptyset(\theta)=(F+G) \cos \sqrt{\delta_{2}} \theta+i(F-G) \sin \sqrt{\delta_{2}} \theta
$$

Selanjutnya, dimisalkan $g$ untuk $(F+G)$ dan $h$ untuk $i(F-G)$, maka persamaan di atas akan menjadi

$$
\emptyset(\theta)=g \cos \sqrt{\delta_{2}} \theta+h \sin \sqrt{\delta_{2}} \theta
$$

Pada persamaan (27), dimisalkan $\delta_{2}=n^{2}$ maka $n=\sqrt{\delta_{2}}$. Oleh karena itu, akan diperoleh,

$$
\varnothing(\theta)=g \cos n \theta+h \sin n \theta
$$

Berdasarkan syarat batas pada persamaan (17), maka akan diperoleh,

$$
\begin{gathered}
u(r, 0)=R(r) \emptyset(0) \\
u(r, 2 \pi)=R(r) \emptyset(2 \pi)
\end{gathered}
$$

Jika $R(r) \neq 0$, maka $\emptyset(0)=0$ dan $\emptyset(2 \pi)=0$. Mensubtitusi persamaan batas ini ke persamaan (27a), akan menjadi,

Jika disubtitusikan $\emptyset(0)=0$ maka,

$$
\varnothing(0)=g .1+0, \text { dengan } h \neq 0
$$

Jika disubtitusi $\varnothing(2 \pi)=0$ maka,

$$
\emptyset(2 \pi)=g \cos n \cdot(2 \pi)+h \sin n \cdot(2 \pi)
$$

Berdasarkan persamaan (28), maka akan dipilih $h \neq 0$, persamaan di atas menjadi,

$$
\emptyset_{n}(0)=h \sin 2 n \pi
$$

Dengan $\emptyset(\theta)$ adalah sebuah fungsi periodik dengan periode $2 \pi$, dan $n=0,1,2,3, \cdots$

Selanjutnya, mencari penyelesaian dari fungsi $R(r)$, berdasarkan persamaan (24), yaitu

$$
\begin{aligned}
& \delta_{2} R(r)=r \frac{\partial}{\partial r} R(r)+r^{2} \frac{\partial^{2}}{\partial r^{2}} R(r)+\delta_{1} r^{2} R(r) \\
& \Leftrightarrow \quad 0=r \frac{\partial}{\partial r} R(r)+r^{2} \frac{\partial^{2}}{\partial r^{2}} R(r)+\left(\delta_{1}-\delta_{2}\right) r^{2} R(r)
\end{aligned}
$$


Berdasarkan persamaan (31), untuk mempermudah penyelesaian akan dimisalkan, $s^{2}=r^{2}\left(\delta_{1}-\delta_{2}\right)$, oleh karena itu $s=r \sqrt{\left(\delta_{1}-\delta_{2}\right)}$. Akan dicari turunan pertama dan kedua, dari fungsi $R(r)$ terhadap $s=r \sqrt{\left(\delta_{1}-\delta_{2}\right)}$, sehingga akan diperoleh,

Turunan pertama,

$$
\frac{\partial R}{\partial r}=\frac{\partial R}{\partial s} \sqrt{\left(\delta_{1}-\delta_{2}\right)}
$$

Turunan kedua,

$$
\frac{\partial^{2} R}{\partial r^{2}}=\frac{\partial^{2} R}{\partial s^{2}} \cdot\left(\delta_{1}-\delta_{2}\right)
$$

Persamaan (32) dan (33) disubtitusi ke persamaan (31) maka akan diperoleh,

$$
s \frac{\partial}{\partial r} R(r)+s \frac{\partial^{2}}{\partial r^{2}} R(r)+s^{2} R(r)=0
$$

Atau dapat ditulis dengan bentuk

$$
s^{2} R^{\prime \prime}+s R^{\prime}+s^{2} R=0
$$

Berdasarkan persamaan (34) dapat dilihat bahwa, ini adalah persamaan diferensial Bessel. Selanjutnya akan diselesaikan fungsi $R(r)$ dengan menggunakan persamaan diferensial Bessel. Penyelesaian fungsi $R(s)$ adalah

$$
R(s)=c_{1} J_{0}(s)+c_{2} Y_{0}(s)
$$

Oleh karena itu, penyelesaian dari fungsi $R(s)$ adalah,

$$
\begin{aligned}
R(s) & =c_{1} J_{0}(s)+c_{2} Y_{0}(s) \\
& =c_{1}\left(\sum_{k=0}^{\infty} \frac{(-1)^{k}}{2^{2 k}(1 !)^{2}}\right)+c_{2}\left(\frac{2}{\pi}\left[J_{0}(s)\left(\ln \frac{s}{2}+\gamma\right)\right]+\sum_{k=0}^{\infty} \frac{(-1)^{k-1}}{2^{2 k}(k !)^{2}} s^{2 k}\right)
\end{aligned}
$$

Jika disubtitusikan kondisi batas $s=0$ kedalam persamaan (36) maka diperoleh,

$$
\begin{gathered}
R(0)=c_{1} J_{0}(0)+c_{2} Y_{0}(0) \\
\Leftrightarrow c_{2}=0
\end{gathered}
$$

Untuk memperoleh solusi yang non-trivial dari persamaan (36), dipilih $c_{1} \neq 0$ maka diperoleh,

$$
R(r)=c_{1}\left(\sum_{k=0}^{\infty} \frac{(-1)^{k}}{2^{2 k}(1 !)^{2}} s^{2 k}\right)
$$

Selanjutnya, karena $s=r \sqrt{\left(\delta_{1}-\delta_{2}\right)}$ maka persamaan (37) menjadi,

$$
R(r)=c_{1}\left(\sum_{k=0}^{\infty} \frac{(-1)^{k}}{2^{2 k}(1 !)^{2}}\left(r \sqrt{\left(\delta_{1}-\delta_{2}\right)}\right)^{2 k}\right)
$$


Oleh karena itu fungsi $R(r)$ adalah

$$
c_{1}\left[J_{0}\left(r \sqrt{\left(\delta_{1}-\delta_{2}\right)}\right)\right]
$$

Sehingga, berdasarkan (22), (30), dan (38) dan prinsip superposisi diperoleh penyelesaian persamaan panas pada koordinat kutub dua dimensi yaitu,

$$
u(r, \theta, t)=\left(C_{n} \sin 2 n \pi\right) J_{0}\left(r \sqrt{\left(\delta_{1}-\delta_{2}\right)}\right) e^{-\delta_{1} \alpha t}
$$

Syarat awal dari persamaan (18) yaitu, $u(r, \theta, 0)=u_{0}$ sehingga diperoleh,

$$
u_{0}=\left(C_{n} \sin 2 n \pi\right) J_{0}\left(r \sqrt{\left(\delta_{1}-\delta_{2}\right)}\right)
$$

Berdasarkan persamaan (39), akan dicari $C_{n}$ merupakan sebuah koefisien tertentu, maka untuk menentukan nilai $C_{n}$ dapat menggunakan deret Fourier. Pada persamaan (39) digunakan akan diubah menjadi deret-fourier Bessel menjadi,

$$
u_{0}=C_{n} J_{0}\left(r \sqrt{\left(\delta_{1}-\delta_{2}\right)}\right)
$$

Ruas kanan dan kiri dikalikan dengan $J_{0}\left(r \sqrt{\left(\delta_{1}-\delta_{2}\right)}\right)$, dan kemudian di integralkan maka akan diperoleh,

$$
C_{n}=\frac{u_{0}}{\int_{0}^{2 \pi} J_{0}\left(r \sqrt{\left(\delta_{1}-\delta_{2}\right)}\right) \cdot r d r}
$$

Merupakan nilai dari deret fourier Bessel selanjutnya, persamaan (41) disubtitusi ke persamaan (40), maka akan diperoleh

$$
u_{0}=\left(\frac{u_{0}}{\int_{0}^{2 \pi} J_{0}\left(r \sqrt{\left(\delta_{1}-\delta_{2}\right)}\right) \cdot r d r} \sin 2 n \pi\right) J_{0}\left(r \sqrt{\left(\delta_{1}-\delta_{2}\right)}\right)
$$

\section{Kesimpulan}

Berdasarkan pembahasan yang telah dipaparkan dalam penelitian ini yaitu mengenai penerapan persamaan diferensial Bessel order nol pada perpindahan panas benda dua dimensi, maka dapat diambil kesimpulan: penerapan fungsi Bessel order sama dengan nol pada proses perpindahan panas benda dua dimensi yang dapat dimodelkan dalam bentuk persamaan diferensial parsial orde dua sebagai berikut,

$$
\alpha \cdot \frac{\partial u}{\partial t}(r, \theta, t)=\frac{1}{r} \frac{\partial u}{\partial r}+\frac{\partial^{2} u}{\partial r^{2}}+\frac{1}{r^{2}} \frac{\partial^{2} u}{\partial \theta^{2}}
$$

dengan diberikan syarat awal dan batas berikut,

Dengan $u_{0}=0$.

$$
\begin{array}{ll}
u(r, \theta, t)=0 & (r, \theta) 0 \leq r \leq R \\
u(r, \theta, t)=u_{0} & 0 \leq \theta \leq 2 \pi \\
u(r, 0, t)=u_{0} & 0 \leq r \leq R \\
u(r, 2 \pi, t)=u_{0} & 0 \leq r \leq R
\end{array}
$$


maka diperoleh solusi dari penerapan PD Bessel di piringan melingkar adalah,

$$
u(r, \theta, t)=\left(C_{n} \sin \sqrt{\delta_{2 n}}\right) J_{0}\left(r \sqrt{\left(\delta_{1}-\delta_{2}\right)}\right) e^{-\delta_{1} \alpha t}
$$

Yang menyatakan suhu dua dimensi pada titik $(r, \theta)$ terhadap waktu $t$.

\section{Referensi}

[1] Holman, J.P., (1990), Heat Transfer, McGraw-Hill, New York. 